\title{
Towards a Better Understanding of Somatic Embryogenesis in Cyclamen persicum
}

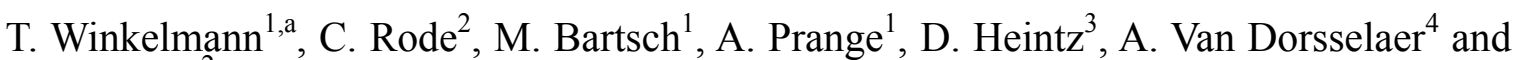
H.-P. Braun ${ }^{2}$

${ }^{1}$ Institute of Floriculture and Woody Plant Science, Leibniz Universität Hannover, Herrenhäuser Str. 2, D-30419 Hannover, Germany

2 Institute of Plant Genetics, Leibniz Universität Hannover, Herrenhäuser Str. 2, D-30419 Hannover, Germany

${ }^{3}$ Institute de Biologie Moléculaire des Plantes (IBMP) CNRS-UPR2357,ULP, F-67083 Strasbourg, France

${ }^{4}$ Laboratoire de Spectrométrie de Masse Bio-Organique, IPHC-DSA, ULP, CNRS, UMR7178; 25 rue Becquerel, F-67087 Strasbourg, France

Keywords: breeding support, mass propagation, ornamental plant, proteomics, zygotic embryogenesis

Abbreviations: 2D: two-dimensional; EST: expressed sequence tag; IEF-SDS PAGE: isoelectric focusing - sodium dodecyl sulfate polyacrylamide gel electrophoresis; MS: mass spectrometry; PGR: plant growth regulator

\begin{abstract}
Somatic embryogenesis in Cyclamen persicum was first reported in 1984 and has potential applications for propagation and breeding of this economically important ornamental crop. This in vitro regeneration system can be used for vegetative propagation of parental lines of $F_{1}$ hybrids and elite plants, production of artificial seeds, Agrobacterium tumefaciens-mediated genetic transformation, long-term cryopreservation, protoplast to plant regeneration and somatic hybridization. Somatic embryogenesis was shown to be a powerful propagation system for some $C$. persicum genotypes, but commercial application in large scale so far is hindered by several limitations, i.e., asynchronous development, malformations or secondary somatic embryogenesis. However, recent molecular approaches by transcriptomic and proteomic analyses were undertaken in order to better understand and control this in vitro regeneration system and to overcome these problems. Our studies aim at comparing somatic embryos to their zygotic counterparts regarding their proteomes. Protein separation by two dimensional isoelectric focusing - sodium do-decyl sulfate polyacrylamide gel electrophoresis led to a resolution of about 1000 protein spots per gel, of which the first 253 were identified by mass spectrometry. Most were found to be involved in glycolysis/gluconeogenesis and stress response pathways. A proteome reference map of zygotic embryos will be publicly released soon and may serve as a basis for further investigations and improvements of somatic embryogenesis.
\end{abstract}

\section{INTRODUCTION}

Somatic embryogenesis is a fascinating plant regeneration pathway which on the one hand may be used to study embryogenesis in easily accessible material or on the other hand may be applied in efficient plant propagation. While classical model plants for somatic embryogenesis were carrot (Steward et al., 1958; Reinert, 1959), alfalfa (Dudits et al., 1991) or conifers (for review see Cairney and Pullman, 2007), for the ornamental plant cyclamen (Cyclamen persicum Mill.) practical knowledge and molecular data have been collected in the last 25 years since the first scientific description by Wicart et al. (1984).

This paper aims to review the applications of somatic embryogenesis for propagation and breeding of cyclamen and to provide an overview of the transcriptomic and proteomic studies of this process supplemented by recent findings of our group.

\footnotetext{
a traud.winkelmann@zier.uni-hannover.de
} 


\section{SOMATIC EMBRYOGENESIS IN CYCLAMEN PERSICUM}

\section{Introduction of the Regeneration Pathway}

In Europe and Japan cyclamen is well known as an ornamental pot plant with an estimated annual worldwide production of 150-200 million plants. Cyclamen are seed propagated, and due to high costs for manual pollination seeds are expensive (up to $0.20 €$ per seed). $F_{1}$ hybrids are dominating the market, but their production is difficult because of inbreeding depressions that occur after a few generations of selfing. Thus, breeders are interested in vegetative propagation of their breeding lines. Moreover, clonal varieties could be obtained by multiplying selected elite plants if an efficient vegetative propagation system was developed. Vegetative propagation in cyclamen needs in vitro techniques since cuttings or tuber division are not applicable. Somatic embryogenesis was described for the first time in cyclamen by Wicart et al. (1984) and has since then been subjected to many optimizing studies resulting in protocols developed for different plant materials and genotypes (Table 1). Advantages compared to adventitious shoot formation were seen in higher propagation rates, lower frequencies of somaclonal variation and early tuber formation resulting in characteristic growth after acclimatization.

In the following we will describe the protocol established in our group in more detail: one aim was to start with explants taken from adult plants without destroying the explant donor (Schwenkel and Winkelmann, 1998; Winkelmann, 2010). Ovules which are available in high numbers of 150-200 per flower bud were found to be highly suitable and offered the additional advantage that contaminations were rarely observed (Winkelmann and Serek, 2005). Somatic cells within the ovules start to divide and give rise to callus formation on 2,4-D containing medium. Depending on the genotype, embryogenic cell cultures can be obtained in different frequencies and can be maintained in 2,4-D containing solid or liquid medium. The trigger for differentiation of somatic embryos is provided by transfer to PGR free medium on which somatic embryos develop to the torpedo stage within three to four weeks. Further conversion into plantlets takes another six to eight weeks of culture in darkness. Conversion rates of $80-90 \%$ were observed for somatic embryos developing on solid medium (Schwenkel and Winkelmann, 1998; Schwenkel, 2001) and between 20\% (Hohe et al., 2001) for non-selected and up to 97\% (Winkelmann et al., 2004b) for selected embryos which had differentiated in liquid medium. To achieve high germination percentages, it turned out to be important to select normally shaped somatic embryos with beginning cotyledon formation.

Schwenkel (2001) reported that 6,000 to 8,000 young plants acclimatized to greenhouse conditions could be obtained within 42 weeks starting from ovules of a single flower bud. In liquid culture systems within 38 weeks 27,000 young plants are within reach, starting from $1 \mathrm{~L}$ of a differentiating culture (Hohe et al., 2001). However, the regeneration rates were found to be variable between genotypes (Püschel et al., 2003; Winkelmann and Serek, 2005). The last step affecting the plant propagation efficiency of an in vitro regeneration system is the acclimatization to greenhouse conditions. For cyclamen, transfer to soil was successful with rates up to $95 \%$ if the plants were of a good quality, i.e., having two to three leaves, a tuber and roots, and if they were adapted to the new growing conditions carefully (Schwenkel and Winkelmann, 1998).

\section{Applications of Somatic Embryogenesis in Propagation and Breeding of Cyclamen}

Since cyclamen suffer from inbreeding depressions propagation of parental lines of $F_{1}$ hybrids by seeds is difficult. Breeders were interested to use somatic embryogenesis for clonal multiplication of parental lines which are needed in numbers of 500 to 1,000 plants per line. Although inbred lines might be less responsive in terms of regeneration efficiency than $F_{1}$ hybrids this relatively low amount of plants can be produced in most cases via somatic embryogenesis. Moreover, embryogenic cultures were successfully cryopreserved enabling long-term storage of germplasm (Winkelmann et al., 2004a).

Another proof of the applicability of the regeneration protocol was given for vegetative propagation of sterile interspecific hybrids between Cyclamen persicum and 
C. purpurascens (Ewald, 1996; Ewald et al., 2000). Out of 2,295 regenerated hybrid plants, $95.4 \%$ were true-to-type, confirming the high stability obtained in this regeneration system. The types of aberrations, which were observed, comprised changed flower colours and tetraploidy (Ewald et al., 2000). The interspecific hybrids were propagated via somatic embryogenesis in a commercial scale of more than 200,000 plants per year.

First steps towards artificial seed production were undertaken by working out conditions for desiccation (Winkelmann et al., 2004b; Seyring and Hohe, 2005) and encapsulation (Winkelmann et al., 2004c) of somatic embryos.

Agrobacterium-mediated transformation will establish a new basis in breeding cyclamen that can result in the introduction of novel flower colours (Boase et al., 2010), heat or frost tolerance or disease resistance. Somatic embryos were successfully used as targets recently (Terakawa et al., 2008), while other authors preferred regeneration via adventitious shoot formation (Boase et al., 2010).

Finally, embryogenic cultures were shown to be an ideal material for protoplast isolation, not only in case of Cyclamen persicum (Winkelmann et al., 2006a), but also in C. coum (Prange et al., 2010a) and C. mirabile, C. graecum and C. trochopteranthum (Prange et al., 2010b). Thus, the prerequisites for somatic hybridization as new breeding instruments are fulfilled. Wild cyclamen species can be expected to provide breeders with interesting traits like fragrance, new leaf shapes and patterns as well as tolerances to biotic and abiotic stresses.

\section{Limitations and Drawbacks of Somatic Embryogenesis in Cyclamen}

The current limited application of somatic embryogenesis in cyclamen breeding and propagation is due to several problems: one of the major difficulties is the lack of synchrony in the development of somatic embryos. In addition, the genotypic differences in responsiveness restrict the use of this regeneration system. If the embryogenic cultures are maintained over longer time on 2,4-D containing medium - in solid, and more pronounced in liquid culture - the risk of mutations and loss of embryogenicity hand increases (Borchert et al., 2007; Winkelmann et al., 2008). Therefore, it is strongly recommended either to establish fresh cultures every two years or to cryopreserve cell lines. Eventually, malformations of somatic embryos like missing organs, secondary embryogenesis, browning, or hyperhydricity were observed.

In order to overcome these problems a better understanding of the physiological processes involved in somatic embryogenesis is needed. Thereby, the empirical adaptation of protocols might be replaced or at least accelerated in future. For cyclamen, a nonmodel plant with limited molecular information, during the last years first insights into somatic embryogenesis were gained by transcriptomic and proteomic studies, which will be surveyed in the following.

\section{PROTEOMIC AND TRANSCRIPTOMIC ANALYSES}

Until recently, knowledge on the molecular biology of $C$. persicum was rather limited but improved very much with the establishment of an expressed sequence tag (EST) library from different stages of somatic embryos and embryogenic cultures (Rensing et al., 2005) and the use of these data in cDNA microarray and real-time PCR expression profiling (Hoenemann et al., 2010). These transcriptomic studies were complemented by the proteomic studies comparing zygotic versus somatic embryos (Winkelmann et al., 2006b), embryogenic versus non-embryogenic cultures (Lyngved et al., 2008) and somatic and zygotic embryos versus non-embryogenic cultures (Bian et al., 2010) performed in the same species. These studies gave new insights into the biochemical changes during cyclamen somatic embryogenesis that revealed many molecular similarities to other somatic embryo systems, such as the one established in carrot (Zimmerman, 1993; Rensing et al., 2005). Typical genes (or specific isoforms of those genes) such as specific genes involved in signal transduction (somatic embryo receptorlike kinases (SERKs), GTP-binding proteins), heat shock proteins (HSPs), peroxidases, 
late embryogenesis abundant (LEA) proteins, arabinogalactan proteins (AGPs) and chitinases, have often been observed to play essential roles during somatic embryogenesis (Winkelmann et al., 2006b; Lyngved et al., 2008; Hoenemann et al., 2010).

In comparative studies of different stages in somatic embryos of $C$. persicum, Hoenemann et al. (2010) observed an overexpression of a chitinase gene and a peroxidase gene three days after somatic embryo induction. The authors deduced that the endochitinases play an essential role in protoderm formation, which presumably is necessary for proper embryo development.

Stress response has been identified as one key pathway in somatic as well as zygotic embryogenesis. In comparisons of the expression profiles of somatic and zygotic embryos of C. persicum, different specific glutathione S-transferases (GST), a superoxide dismutase (SOD), catalase and two cytochrome P450 homologues were found to be upregulated in early-stage somatic embryos (after auxin removal) (Hoenemann et al., 2010). Winkelmann et al. (2006b) identified a highly abundant SOD in both embryo types of C. persicum. These enzymes are involved in oxidative stress response and are active in other cellular detoxification processes. A connection between oxidative stress and somatic embryogenesis has been suggested by many authors.

These recent combined efforts are just a starting point on the way to understand this complex regeneration pathway. In order to go into more detailed analyses we further followed the proteomic comparison of somatic embryos to their zygotic counterparts, because we are convinced that the physiology of zygotic embryos can be regarded as ideal state, and any differences detected in somatic embryos point to possibilities to improve the system of somatic embryogenesis (Rode et al., 2011).

\section{MATERIALS AND METHODS}

Zygotic and somatic embryos of the C. persicum cultivar 'Maxora Light Purple' (Varinova BV, Berkel en Rodenrijs, The Netherlands) were harvested at the torpedo stage (Rode et al., 2011). Zygotic embryos were prepared from seeds 11 weeks after selfpollination, while somatic embryos were produced from embryogenic suspension cultures as described by Winkelmann et al. (1998). One $\mathrm{ml}$ of a 500-1000 $\mu \mathrm{m}$ cell fraction of the suspension adjusted to a density of $10 \%$ packed cell volume was plated onto PGR-free medium. After four weeks of incubation at $24^{\circ} \mathrm{C}$ in the dark, torpedo-shaped embryos were harvested. Both tissues were frozen in liquid nitrogen directly after harvesting and pulverized in a bead mill.

Total proteins were extracted from $80 \mathrm{mg}$ of tissue according to the protocol of Hurkman and Tanaka (1986) modified by Colditz et al. (2004) in four biological and technical replicates each. Complete protein extracts were separated via IEF-SDS PAGE as described by Winkelmann et al. (2006b), but using immobiline dry strip gels with a $\mathrm{pH}$ gradient of 3-11. Gels were scanned and analysed using Delta 2D version 4.0 software (Decodon, Greifswald, Germany). At least 1.5 -fold alterations (statistically proven by Student's t-test) in protein abundance among both analysed groups were considered to represent true differences in protein levels. The 300 most abundant or differentially expressed protein spots were picked manually from gels. In gel digestion of protein spots and nano-LC-MS/MS analyses as well as protein database searches against TAIR9, GreenPlant, and NCBI were performed as described by Fuehrs et al. (2009).

For installing a proteome reference map of cyclamen embryos, a novel software tool named "GelMap" was programmed using PHP scripting language on a standard MySQL version 5.0 database code (Sun Microsystems, Santa Clara, USA) and will be made publically available at the website: www.genetik.uni-hannover.de/cyclamen.html (Rode et al., 2011).

\section{RESULTS AND DISCUSSION}

Proteins of somatic and zygotic embryos were separated by 2D IEF-SDS PAGE resulting in gels of high resolution. In average, a total of more than 1000 spots were reproducibly resolved. Although a different genotype and a different protein extraction 
protocol was used as compared to our previous study (Winkelmann et al., 2006b), corresponding percentages of specific abundances were found: 137 protein spots were at least 1.5-fold higher in abundance in the zygotic embryo proteome, whereas 109 protein spots were at least 1.5-fold more abundant in the somatic embryo proteome.

Interestingly, the MS based protein identification rate could be increased to $87 \%$ of the eluted protein spots (261 out of 300, Table 2) also due to the fact that the number of available sequences in public databases has been increased. This protein identification rate was quite high, even though Cyclamen persicum has no close relatives within the sequenced plants, illustrating that protein identification in non-model organisms becomes more and more successful.

The most prominent proteins identified that were significantly more abundant either in zygotic or in somatic embryos are listed in Table 3. One noticeable outcome of this comparison is the predominance of stress response proteins within the group of highly abundant proteins of somatic embryos. This is further support of the above mentioned important role of stress reactions for somatic embryogenesis. Further remarkable results are the high abundance of proteins involved in carbohydrate metabolism found in zygotic embryos (Fig. 1, Table 3). Enolases were the most often detected protein (Fig. 1) and interestingly were not only identified in spots of the expected size range of $50 \mathrm{kDa}$, but also in a high number of spots with a lower molecular in gel weight. For us, this is evidence for truncated enolases to be candidates for a novel group of storage compounds in seeds (Rode et al., 2011).

Using a newly developed software named "GelMap" a digital proteome reference map was created. On a gel image, the protein spots identified via MS are marked and can be clicked on to see further information on this protein including a link to the KEGG PATHWAY database for proteins of interest and if available, the protein EC classification linked to ExPASy Proteomics server. Furthermore, protein spots can be filtered by their physiological function as well as their source, regulation, protein name and spot ID. All deposited data will be accessible online and this platform is intended to support future studies on development and maturation of somatic and zygotic cyclamen embryos.

\section{CONCLUSIONS}

The use of somatic embryogenesis for large-scale propagation and breeding of Cyclamen persicum is limited due to physiological disorders and asynchronous development. Unravelling this process by proteomic and transcriptomic approaches is at the beginning, but in future insights into embryogenesis can be expected to be useful for improving in vitro regeneration protocols.

\section{ACKNOWLEDGEMENTS}

The authors would like to thank Michael Senkler for programming "GelMap" and computer related assistance and the DFG (Deutsche Forschungsgemeinschaft - German Research Founding) for financial support.

\section{Literature Cited}

Bach, A., Malik, M. and Zolneczko, B. 1998. Organogenesis and somatic embryogenesis in cultures of Cyclamen persicum Mill. F ' 'Medium'. Acta Biol. Cracov. 40:47-51.

Bian, F., Zheng, C., Qu, F., Gong, X. and You, C. 2010. Proteomic analysis of somatic embryogenesis in Cyclamen persicum Mill. Plant Mol. Biol. Rep. 28:22-31.

Boase, M.R., Lewis, D.H., Davies, K.M., Marshall, G.B., Patel, D., Schwinn, K.E. and Deroles, S.C. 2010. Isolation and antisense suppression of flavonoid 3',5'-hydroxylase modifies flower pigments and colour in cyclamen. BMC Plant Biology 10:107 http://www.biomedcentral.com/1471-2229/10/107.

Borchert, T., Fuchs, J., Winkelmann, T. and Hohe, A. 2007. Variable DNA content of Cyclamen persicum regenerated via somatic embryogenesis: rethinking the concept of long-term callus and suspension cultures. Plant Cell Tiss. Org. Cult. 90:255-263.

Cairney, J. and Pullman, G.S. 2007. The cellular and molecular biology of conifer 
embryogenesis. New Phytologist 176:511-536.

Colditz, F., Nyamsuren, O., Niehaus, H., Eubel, H., Braun, H.-P. and Krajinski, F. 2004. Proteomic approach: identification of Medicago truncatula proteins induced in roots after infection with the pathogenic oomycete Aphanomyces euteiches. Plant. Mol. Biol. 55:109-120.

Dudits, D., Bogre, L. and Gyorgyey, J. 1991. Molecular and cellular approaches to the analysis of plant embryo development from somatic cells in vitro. J. Cell Sci. 99:475484.

Ewald, A. 1996. Interspecific hybridization between Cyclamen persicum Mill. And C. purpurascens Mill. Plant Breed. 115:162-166.

Ewald, A., Orlicz, L.A., Winkelmann, T. and Schwenkel, H.G. 2000. Interspecific hybrids of Cyclamen persicum Mill. X Cyclamen purpurascens Mill.: propagation, somaclonal variation, resistance to Fusarium wilt and suitability as an outdoor crop. Acta Hort. 508:309-310.

Fuehrs, H., Goetze, S., Specht, A., Erban, A., Gallien, S., Heintz, D., Van Dorsselaer, A., Kopka, J., Braun, H.P. and Horst, W.J. 2009. Characterization of leaf apoplastic peroxidases and metabolites in Vigna unguiculata in response to toxic manganese supply and silicon. J. Exp. Bot. 60:1663-1678.

Fukui, H., Yamamoto, T., Asano, T. and Nakamura, M. 1988. Effect of plant growth regulators on in vitro organogenesis of cyclamen (Cyclamen persicum Mill.). Res. Bull. Fac. Agr. Gifu Univ. 53:139-145.

Hoenemann, C., Richardt, S., Krüger, K., Zimmer, A.D., Hohe, A. and Rensing, S.A. 2010. Large impact pact of the apoplast on somatic embryogenesis in Cyclamen persicum offers possibilities for improved developmental control in vitro. BMC Plant Biology 10:77 http://www.biomedcentral.com/1471-2229/10/77.

Hohe, A., Winkelmann, T. and Schwenkel, H.-G. 2001. Development of somatic embryos of Cyclamen persicum Mill. in liquid culture. Gartenbauwissenschaft 66:219-224.

Hurkman, W.J. and Tanaka, C.K. 1986. Solubilization of plant membrane proteins for analysis by two-dimensional gel electrophoresis. Plant Physiol. 81:802-806.

Kiviharju, E., Tuominen, U. and Törmälä, T. 1992. The effect of explant material on somatic embryogenesis of Cyclamen persicum Mill. Plant Cell Tiss. Org. Cult. 28:187-194.

Kreuger, M., Postma, E., Brouwer, Y. and van Holst, G.J. 1995. Somatic embryogenesis of Cyclamen persicum in liquid medium. Physiol. Plant. 94:605-612.

Lyngved, R., Renaut, J., Hausman, J.-F., Iversen, T.-H. and Hvoslef-Eide, A.K. 2008. Embryo-specific proteins in Cyclamen persicum analyzed with 2-D DIGE. J. Plant Growth Regul. 27:353-369.

Otani, M. and Shimada, T. 1991. Somatic embryogenesis and plant regeneration from Cyclamen persicum Mill. leaf cultures. Plant Tiss. Cult. Lett. 8:121-123.

Prange, A.N.S., Serek, M., Bartsch, M. and Winkelmann, T. 2010a. Efficient and stable regeneration from protoplasts of Cyclamen coum Miller via somatic embryogenesis. Plant Cell Tiss. Org. Cult. 101:171-182.

Prange, A.N.S., Bartsch, M., Serek, M. and Winkelmann, T. 2010b. Regeneration of different Cyclamen species via somatic embryogenesis from callus, suspension cultures and protoplasts. Scientia Hort. 125:442-450.

Püschel, A.-K., Schwenkel H.-G. and Winkelmann, T. 2003. Inheritance of the ability for regeneration via somatic embryogenesis in Cyclamen persicum Mill. Plant Cell Tiss. Org. Cult. 72:43-51.

Reinert, J. 1959. Morphogenese und ihre Kontrolle an Gewebekulturen aus Carotten. Naturwissenschaften 45:344-345.

Rensing, S.A., Lang, D., Schumann, E., Reski, R. and Hohe, A. 2005. EST sequencing from embryogenic Cyclamen persicum cell cultures identifies a high proportion of transcripts homologous to plant genes involved in somatic embryogenesis. J. Plant Growth Regul. 24:102-115.

Rode, C., Gallien, S., Heintz, D., van Dorsselaer, A., Braun, H.-P. and Winkelmann, T. 
2011. Enolases: storage compounds in seeds? Evidence from a proteomic comparison of zygotic and somatic embryos of Cyclamen persicum Mill. Plant Mol. Biol. 75:305319.

Schwenkel, H.-G. 2001. Development of a reproducible regeneration protocol. p.8-11. In: H.-G. Schwenkel (ed.), Reproduction of Cyclamen persicum Mill. through somatic embryogenesis using suspension culture systems. European Communities, 2001.

Schwenkel, H.-G. and Winkelmann, T. 1998. Plant regeneration via somatic embryogenesis from ovules of Cyclamen persicum Mill. Plant Tiss. Cult. Biotechnol. 4:28-34.

Seyring, M. and Hohe, A. 2005. Induction of desiccation tolerance in somatic embryos of C. persicum Mill. J. Hortic. Sci. Biotechnol. 80:65-69.

Steward, F.C., Mapes, M.O. and Smith, J. 1958. Growth and organized development of cultured cells. I. Growth and division of freely suspended cells. Am. J. Bot. 45:693703.

Takamura, T. and Tanaka, M. 1996. Somatic embryogenesis from the etiolated petiole of cyclamen (Cyclamen persicum Mill.). Plant Tiss. Cult. Lett. 13:43-48.

Takamura, T., Miyajima, I. and Matsuo, E. 1995. Somatic embryogenesis of Cyclamen persicum Mill. 'Anneke' from aseptic seedlings. Plant Cell Rep. 15:22-25.

Terakawa, T., Yamamura, T. and Murayama, T. 2008. Improvement of regeneration and transformation systems for Cyclamen persicum using somatic embryo culture. Plant Biotechnol 25:77-80.

Wicart, G., Mouras, A. and Lutz, A. 1984. Histological study of organogenesis and embryogenesis in Cyclamen persicum tissue cultures: evidence for a single organogenetic pattern. Protoplasma 119:159-167.

Winkelmann, T. 2010. Clonal propagation of Cyclamen persicum via somatic embryogenesis. p.281-290. In: S.M. Jain and S.J. Ochatt (eds.), Protocols for in vitro propagation of ornamental plants. Vol. 589, Methods in Molecular Biology. SpringerVerlag Berlin, Heidelberg.

Winkelmann, T. and Serek, M. 2005. Genotypic differences in callus formation and regeneration of somatic embryos in Cyclamen persicum Mill. Euphyt. 144:109-116.

Winkelmann, T., Hohe, A. and Schwenkel, H.G. 1998. Establishing embryogenic suspension cultures in Cyclamen persicum 'Purple Flamed'. Adv. Hortic. Sci. 12:2530.

Winkelmann, T., Mußmann, V. and Serek, M. 2004a. Cryopreservation of embryogenic suspension cultures of Cyclamen persicum Mill. Plant Cell Rep. 23:1-8.

Winkelmann, T., Meyer, L. and Serek, M. 2004b Desiccation of somatic embryos of Cyclamen persicum Mill. J. Horticult. Sci. Biotechnol. 79:479-483.

Winkelmann, T., Meyer, L. and Serek, M. 2004c. Germination of encapsulated somatic embryos of Cyclamen persicum. HortScience 39:1093-1097.

Winkelmann, T., Specht, J. and Serek, M. 2006a. Efficient plant regeneration from protoplasts isolated from embryogenic suspension cultures of Cyclamen persicum Mill. Plant Cell Tiss. Org. Cult. 86:337-347.

Winkelmann, T., Heintz, D., Van Dorsselaer, A., Serek, M. and Braun, H.-P. 2006b. Proteomic analyses of somatic and zygotic embryos of Cyclamen persicum Mill. reveal new insights into seed and germination physiology. Planta 224:508-519.

Winkelmann, T., Prange, A.N.S., Specht, J. and Serek, M. 2008. Morphological characterization of plants regenerated from protoplasts of Cyclamen persicum Mill. J. Prop. Ornam. Plants 8:9-12.

Zimmerman, J.L. 1993. Somatic embryogenesis - a model for early development in higher plants. Plant Cell 5:1411-1423. 


\section{Tables}

Table 1. Somatic embryogenesis in Cyclamen persicum - a literature survey listing the publications dealing with establishing the regeneration pathway.

\begin{tabular}{lcc}
\hline Year & Explant type & Reference \\
\hline 1984 & leaf blades, petioles, ovaries & Wicart et al. (1984) \\
1988 & parts of seedlings & Fukui et al. (1988) \\
1991 & young leaf blades & Otani and Shimada (1991) \\
1992 & anthers, ovaries, zygotic embryos & Kiviharju et al. (1992) \\
1995 & seedling tubers & Kreuger et al. (1995) \\
1995 & parts of seedlings & Takamura et al. (1995) \\
1996 & etiolated petioles & Takamura and Tanaka (1996) \\
1998 & parts of seedlings & Bach et al. (1998) \\
1998 & Ovules, anthers, peduncles, sepals & Schwenkel and Winkelmann (1998) \\
\hline
\end{tabular}

Table 2. Protein identification rate by mass spectrometry.

\begin{tabular}{lccc}
\hline & Zygotic embryos & Somatic embryos & Total \\
\hline Spots eluted & 900 & 37 & 937 \\
Analysed by mass spectrometry & 263 & 37 & 300 \\
Proteins identified & 229 & 32 & 261 \\
\hline Protein identification rate & $87 \%$ & $86 \%$ & $87 \%$ \\
\hline
\end{tabular}

Table 3. Proteins being significantly more abundant in one tissue.

\begin{tabular}{|c|c|c|c|}
\hline \multicolumn{2}{|c|}{ More abundant in zygotic embryos } & \multicolumn{2}{|c|}{ More abundant in somatic embryos } \\
\hline Protein & Function & Protein & Function \\
\hline Oxidoreductase & $\begin{array}{l}\text { Other metabolic } \\
\text { processes }\end{array}$ & Osmotin-like protein & Stress response \\
\hline $\begin{array}{l}\text { Succinate/Malate } \\
\text { CoA ligase }\end{array}$ & Tricarboxylic acid cycle & Antioxidant 1 & Stress response \\
\hline $\begin{array}{l}\text { Malate } \\
\text { dehydrogenase }\end{array}$ & $\begin{array}{l}\text { Glycolysis/ } \\
\text { gluconeogenesis }\end{array}$ & Peroxiredoxin type II & Stress response \\
\hline $\begin{array}{l}\text { Voltage-dependent } \\
\text { anion channel }\end{array}$ & Anion transport & Catalase & Stress response \\
\hline $\begin{array}{l}\text { Copper/zinc } \\
\text { superoxide } \\
\text { dismutase }\end{array}$ & Stress response & $\begin{array}{c}\text { Nucleoside } \\
\text { diphosphate kinase }\end{array}$ & $\begin{array}{l}\text { Other } \\
\text { metabolic } \\
\text { processes }\end{array}$ \\
\hline
\end{tabular}




\section{Figures}



Fig. 1. Digital reference map of the Cyclamen persicum zygotic embryo proteome applying a filter in order to visualize the spots identified as enolase 1. By clicking on each labelled spot, specific spot information appears in a pop-up window. Filters selecting identified proteins by their physiological function as well as by their source, regulation, protein name and spot ID are available. 
